\title{
LA CREACIÓN FOTOGRÁFICA: ESPACIO PARA VISIBILIZAR AL APRECIO POR LA BLANCURA
}

\section{Photographic creation: space to make visible the appreciation for whiteness}

\section{Resumen:}

Este artículo describe de qué modo, un proceso de creación fotográfica puede operar como espacio y método para la construcción de conocimientos acerca de cómo se reproducen "el aprecio por la blancura" y el privilegio de "ser güero" en una sociedad mestizófila como la mexicana. Desde un posicionamiento decolonial, analiza la manera en que la ideología mestizante ha detonado impulsos eugenésicos para "depurar" a la población nacional y a su representación simbólica a lo largo de la historia. Muestra cómo un proceso de creación fotográfica puede generar reflexiones, críticas y acciones políticas orientadas a la transformación social de la realidad, a través de visibilizar y erosionar el dominio de la colonialidad del ver y cuestionar la reproducción de ventajas y desventajas en la diversidad que propicia.

\section{Palabras clave:}

fotografía, retrato, racismo, colonialidad, decolonialidad, investigación basada en artes

\section{Abstract:}

This article describes how the process of photographic creation can operate as a space and method for the construction of knowledge about how, "appreciation for whiteness" and the privilege of "being white", are reproduced in Mexico. From a decolonial position, it analyzes the way in which eugenic ideology has detonated impulses to "purify" the national population and its symbolic representation throughout history. It makes proposals about how a process of photographic creation can generate reflections, criticisms and political actions aimed at the social transformation of reality: visualizing and eroding the domain of the coloniality of seeing; and questioning the reproduction of advantages and disadvantages in diversity.

\section{Key Words:}

photography, portrait, racism, coloniality, decoloniality, arts-based research

\section{Biografía de los autores:}

Rodrigo Zárate Moedano. Ciudad de México, 1977. Doctor en Investigación Educativa por la Universidad Veracruza-na, Maestro en Tecnología Educativa por la Universidad Da Vinci, con Estudios Avanzados en Historia del Cine en la Universidad Autónoma de Madrid. Miembro de la Red de Investigación Interdisciplinaria sobre Identidades, Racismo y Xenofobia en América Latina (INTEGRA). Coordinador y docente de la Especialización en Estudios Cinematográficos, y docente de la Licenciatura en Fotografía de la Universidad Veracruzana. Estudia la representación visual y audiovisual de identidades y alteridades, y la reproducción de ideologías de dominación por medio de la creación y consumo de imágenes. 
Luis Joseph Pérez Morales. Coatzacoalcos, Veracruz, México 1993. Egresado de la Licenciatura en Fotografía de la Universidad Veracruzana. En 2016 realizó una estancia en la Universidad Mayor de Santiago de Chile, en su programa de Licenciatura de Cine. Ha participado en la producción de los cortometrajes Malba (México, 2017), Cristóbal (México, 2017), Les Plantes: la passiffore (México 2017) y En el viento y en todas partes (Chile, 2016); y ha trabajado en campañas publicitarias de Calvin Klein (2018) y NOMA (2017). En 2016 fue seleccionado en la Tercera Bienal de Arte de Veracruz, México; y en 2015 recibió el estímulo de creación artística PECDAV.

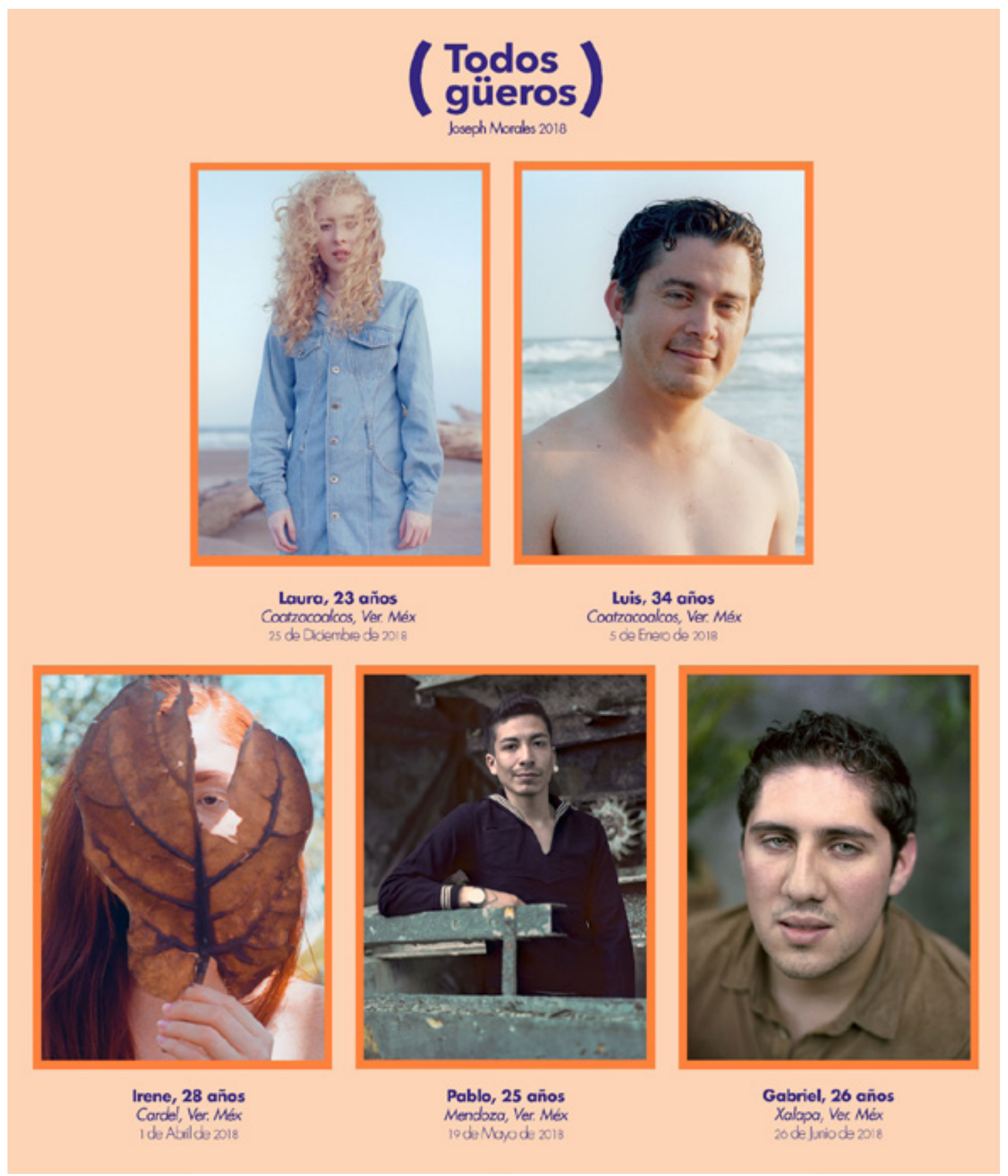

Figura 1. Fotografía de Luis Joseph Pérez Morales. (Xalapa, Veracruz, México, 2018). Archivo personal. 


\section{Introducción}

En un intercambio de mensajes entre los autores de este texto, Joseph recordó la reticencia de algunos de sus profesores de la Licenciatura en Fotografía para que desarrollara su proyecto Todos güeros; argüían que su texto ponía demasiado énfasis en el tema desde la Sociología, la Antropología y la Historia, y muy poco en lo puramente fotográfico. Cuestionó también la pertinencia de privilegiar la formación de fotógrafos como técnicos ejecutantes, por encima de formarlos como actores sociales para crear respuestas visuales a problemáticas diversas utilizando el arte como herramienta. Y desde ese mismo posicionamiento político acerca de la función del arte y del artista en la sociedad, este artículo se enfoca en analizar cómo el desarrollo de Todos güeros detonó la construcción experiencial de conocimientos sobre el modo en que se expresan, se experimentan y se reproducen el aprecio por "la blancura" y el privilegio de "ser güero" en una sociedad mestizófila como la mexicana. Para concluir proponiendo la formación de fotógrafos que asuman el compromiso de hacer de su producción artística instrumento para erradicar el poder e influencia de la colonialidad del ver (Barriendos, 2011).

\section{Investigación basada en la realización de un proyecto fotográfico}

El proceso de investigación del que deriva el artículo parte de entender que el racismo es un sistema de pensamiento que mantiene o exacerba la desigualdad de oportunidades entre grupos sociales diversos y puede ser expresado por medio de estereotipos, prejuicios o actos discriminatorios, en forma de creencias, sentimientos o prácticas; una forma de pensar la identidad y la otredad que prescribe ventajas o desventajas dependiendo de las características de los sujetos (Berman y Paradies, 2008). Para ofrecer una mirada crítica y reflexiva en torno a las políticas y prácticas institucionales que reproducen y refuerzan el aprecio por "la blancura" y el privilegio de "ser güero", el artículo adopta el posicionamiento antirracista de Berman y Paradies.

Es pertinente señalar que el interés del fotógrafo en el tema surgió en Santiago de Chile en 2016, al realizar una estancia de intercambio académico en la Facultad de Artes de la Universidad Mayor. De su conversación con una chica para quien hizo un portafolio fotográfico, le resultaron especialmente interesantes sus relatos acerca del privilegio que había supuesto en su vida ser rubia. Entonces empezó a preguntarse ¿de qué manera influye el color de piel de una persona en su experiencia de vida? Aunque en ese momento no era consciente de que esas conversaciones y la producción de aquellas fotografías, con el tiempo serían el brote germinal de Todos güeros, su proyecto de titulación como Licenciado en Fotografía.

Otra experiencia decisiva fue trabajar como voluntario en Canadá por tres meses en 2017, pues contribuyó a que siguiera profundizando sus reflexiones en torno al aprecio y desprecio que enfrentan sujetos de características físicas diferentes y a esbozar las ideas generales de su proyecto. El detonante fue que lo abordó para decirle que su color de piel morena es "muy bonito", nunca le había ocurrido algo similar ni en México, ni en Chile. De vuelta en México, empezó a documentar su interés leyendo cómo se originan y reproducen la discriminación y el racismo.

Ahora bien, el proceso de investigación se diseñó e implementó sobre la base de la perspectiva de Carrillo Quiroga (2015) acerca de la investigación basada en artes y apuesta por contextualizar el tema de estudio desde la perspectiva de los sujetos - el fotógrafo y los personajes retratados-haciendo que la teoría y la creación artística "se complementen y se informen la una a la otra" para revelar aspectos sociales y culturales del contexto que en el que se realizó la obra. Recuperó testimonios sobre la experiencia de ser "güero"; distinguiendo tres subtemas: 1) la relación del sujeto con la categoría "güero", 2) sus experiencias de privilegio siendo "güeros" y 3) sus experiencias de desventaja. Y analizó su contenido desde una perspectiva teórica decolonial (Zárate-Moedano, 2018) tomando las experiencias individuales de los personajes fotografiados y del fotógrafo como evidencias de un fenómeno sociocultural mayor: la reproducción del racismo.

\section{El "aprecio por la blancura" en la producción de imágenes}

De la investigación documental realizada para contextualizar y sustentar teóricamente la realización del proyecto, destaca en primer lugar, que, como fenómeno estructural, el racismo se reproduce por medio del discurso, en particular del contenido que circula en los medios de comunicación. La producción cultural dominante 
reproduce miradas racistas y coloniales controlando qué tipo de sujeto interpreta a qué tipo de personajes en qué tipo de narrativas, es decir, construyendo una oferta en la que se filtra la diversidad con fines eugenésicos y la "blancura", física y cultural, prevalece como modelo aspiracional. La eugenesia simbólica (Zárate-Moedano, 2018) privilegia la presencia en el cuadro de sujetos de piel clara y tipo europeo, en detrimento de sujetos que sean o parezcan ser "indígenas" o "negros", por ello, por ejemplo, en el cine y la televisión de México es recurrente el blanqueamiento de personajes "indígenas" haciendo que los interpreten actrices o actores "no indígenas", de piel clara y tipo europeo.

Estas prácticas simbólicas son generadas desde una gramática de identidad/alteridad que ha sido configurada con una perspectiva política particular; la de la "ideología mestizante" (Gómez Izquierdo y Sánchez Díaz, 2012), que desde el siglo XIX propone "mejorar la raza" de los sujetos "indígenas" para garantizar el progreso nacional. Son prácticas que asumen la superioridad de "lo europeo" frente a "lo indio" y "lo negro", y por defecto excluyen a los sujetos "que no se amolden al paradigma cultural estético del mestizo", con el fin de "blanquear a la población de piel oscura y rasgos indo-africanos" (Gómez Izquierdo y Sánchez Díaz, 2012: 21). De esa forma legitiman la perspectiva racista y colonial desde la cual se imponen unos determinados parámetros de lo bello y de lo feo.

Dichas prácticas son obra de una sociedad pigmentocrática (Sánchez, 2012), es decir, de un orden social de dominación de origen colonial en el que el color de piel de los sujetos les prescribe una posición determinada dentro de la estructura socioeconómica. La producción simbólica de los medios de comunicación dominantes ha normalizado que "los modelos de éxito, belleza, protagonismo y de reconocimiento social” (Sánchez, 2012, p.1504) sean personificados exclusivamente por personajes a los que, "por su fenotipo y rasgos esencialmente de origen europeo", la gran mayoría de la población mexicana no se parece.

Son recurrentes las denuncias de actrices y actores, como Iazua Larios (Maristain, 2015) y Tenoch Huerta (El Diario, 2016) acerca de las pocas oportunidades que encuentran para actuar en cine y televisión fuera de interpretar a personajes pobres, criminales o sirvientes. O bien, casos como el que describe el reportaje "Los 'representantes de México' no se parecen a los mexicanos" (Molina, 2013), acerca de una convocatoria de la aerolínea Aeroméxico, solicitando actores que representaran a la afición de la selección mexicana de fútbol y tuvieran "perfil internacional”, "piel blanca" y que no parecieran "rancheros", con apariencia de "clase alta" y definitivamente "no morenos".

Los procesos de eugenesia simbólica forman parte de una lógica estructural de la sociedad nacional mexicana; no son excepciones sino la norma $y$, tienen su correlato en otros ámbitos del acontecer nacional. Por ejemplo en el acceso a la educación y al mercado laboral, como lo indica el estudio sobre movilidad social intergeneracional (INEGI, 2017), según el cual mientras más oscuro es el color de piel de los sujetos, los porcentajes de personas ocupadas en actividades de mayor calificación se reducen, al mismo tiempo que cuando se vuelve más claro, los porcentajes de ocupación en actividades de media y alta calificación se incrementan.

\section{Inmigración europea para “mejorar la raza” en Veracruz, México}

En segundo lugar, de la investigación documental realizada para contextualizar y sustentar teóricamente la realización del proyecto, destaca que, a finales del siglo XIX, el pensamiento político conservador tenía en su catálogo de obras admirables el Systema Naturae (1753) de Carl von Linné, que clasificaba las "razas" humanas y luego de combinar observaciones, mediciones y comparaciones empíricas de cada grupo "racial" con juicios de valor moral, concluía que la "raza blanca" era superior a las demás, pues presentaba una mayor cantidad de virtudes "congénitas" (Gómez Izquierdo y Sánchez Díaz, 2012: 41 y 42). Por ello, las clases dominantes de México adoptaron un sistema de pensamiento que establecía una línea divisoria entre humanos biológicamente superiores e inferiores y fundamentaba su lectura de la realidad articulando la clasificación de las "razas" humanas de Linné con una interpretación social de la teoría de la evolución postulada por el naturalista Charles Darwin en El origen de las especies (1859).

Desde el darwinismo social se asumía que, en un contexto de competencia capitalista, tenían lugar procesos de selección natural como mecanismos de evolución social, ante los cuales únicamente sobrevivían los sujetos más aptos. Fundamentada en el darwinismo social, la eugenesia promovía la selección artificial de los más aptos es decir, la "depuración" de las poblaciones controlando 
la reproducción de los sujetos, permitiendo procrear a los que presentaran rasgos identitarios "deseables".

Para defenderse de las "amenazas biológicas" que se reproducían al interior del tejido social, las élites promovían una visión racista del mundo desde el poder del Estado (Gómez Izquierdo, 2005, p. 125). Así, mientras por medio del nacionalismo se buscaba generar una sensación de pertenencia a una comunidad fraternal y solidaria que difuminara las diferencias de la población; por otro lado a través del "racismo biológico" se buscaba destacar las diferencias y abusar psíquicamente del Otro hasta dominarlo simbólica y materialmente.

En ese contexto, para crear la sensación de pertenencia entre los grupos sociales que anteriormente estuvieron divididos en castas, las élites mexicanas establecieron el mestizaje entre padre "peninsular" y madre "india" como mito fundacional de la nación, como el origen común de todos los mexicanos. Al mismo tiempo que, con el objetivo de continuar la relación de dominación sobre los pueblos originarios, construyeron al "indio" como inferior e indeseable para el progreso nacional; por lo cual, para ser parte de la nación los pueblos originarios debían "desindianizarse” (Bonfil Batalla, 2010), es decir, transformarse en "mestizos", "blanquearse".

Para impulsar el blanqueamiento de la población y "mejorar la raza", desde el poder se ofrecieron tierras a colonos europeos (Méndez, 2011, p.303-306). En 1833 llegaron los primeros provenientes de Francia y se asentaron en las comunidades de Jicaltepec y San Rafael al norte del puerto de Veracruz. Entre 1834 y 1837 llegaron colonos alemanes a una comunidad cercana al puerto de Veracruz, aunque no permanecieron en ese lugar debido a las condiciones climatológicas adversas y se ubicaron en cambio en lugares como Huatusco, Córdoba y Orizaba. Posteriormente, en 1858 llegaron colonos italianos y se instalaron en Tecolutla, no muy lejos de los asentamientos franceses de Jicaltepec y San Rafael en 1881 otros italianos se asentaron en la colonia Manuel González, cerca de Huatusco. Hacia finales del siglo XIX había cerca de mil colonos europeos en el estado de Veracruz.

\section{Construir conocimientos sobre el privilegio de ser "güero"}

Ahora bien, en un contexto donde la construcción social de la realidad se lleva y se ha llevado a cabo reproduciendo el "aprecio por la blancura", el proceso de crear la serie fotográfica "Todos güeros" permitió recuperar testimonios acerca de cómo un grupo de sujetos güeros ha experimentado a lo largo de su trayectoria de vida; destacando sus vínculos con la categoría güero y cómo han experimentado privilegios y/o desventajas por ser güeros. Destaca en primer lugar que los cinco personajes retratados coinciden en que, por su apariencia física han sido llamados "güeros" a lo largo de sus trayectorias de vida y han asumido su identidad "güera" a partir de que los otros los definen como tales.

En ese sentido, es revelador el testimonio de Luis: "Yo soy güero por mi color de piel, nada más mírame. Desde siempre me han dicho güero, en todas partes $\mathrm{y}$ pienso que por eso me reconozco como tal" (05/01/2018). Es notable que coinciden en que socialmente parece existir una necesidad de destacar la claridad de su piel, por ello, "todo el tiempo", "toda la vida" esto ha llamado la atención. Al respecto Pablo comenta: "siempre se nos recalca ese hecho, es decir, la constante necesidad de decirnos por nuestro color de piel: güero" (19/05/2018).

En segundo lugar, los testimonios ofrecen evidencias empíricas de cómo el aprecio por la blancura se materializa en privilegios para quienes son identificados como "güeros". Por ejemplo, Gabriel reconoce que ha accedido a educación privada, y no está seguro si por eso haya "convivido más con personas de piel clara que con personas morenas" (26/06/2018), es decir, asume que las desigualdades socioeconómicas se encuentran vinculadas con ser güero o moreno. En cambio para Luis, ser "güero" ha representado acceder a un trato privilegiado de reconocimiento social, y a ninguna desventaja. Recuerda en especial que, siendo niño, "en la escuela era el más güerito", y por eso siempre le daban un lugar especial en los homenajes a la bandera. Además, sugiere que las características estéticas del güero son asociadas a posiciones de privilegio y las de los morenos a posiciones de desventaja; y en ese sentido recuerda que, en un viaje de trabajo con su jefe, "moreno, chaparro, y pues, más panzón" (Luis, 05/01/2018), al llegar a su destino asumieron que él, alto, blanco y de ojos verdes, era el jefe, y su jefe el subordinado, dieron por hecho que el sujeto de mayor jerarquía era el "güero" y el de menor jerarquía el moreno. Por lo cual, piensa que ser güero "te da cierto poder o diferencia”. Cuenta que, a lo largo de su vida, ha recibido "un trato mil veces mejor que muchas de las personas con las que he crecido simplemente por el hecho de ser güero de ojos verdes" (05/01/2018).

Por su parte, Pablo señala que su ciudad de origen, Orizaba, Veracruz, es "hiperracista (...) una ciudad con 
aires de grandeza" (19/05/2018), donde los “indígenas" no son bien recibidos. Recuerda haber experimentado una situación de privilegio similar a la de Luis, por ejemplo, una ocasión mientras fumaba marihuana al caminar por el centro de la ciudad y el policía con el que se cruzó solo le dijo que dejara de hacerlo, cuando a otras personas "cuyas características son más... en cierto modo indígenas (...) por situaciones muchísimo menos graves que fumar mota en la calle les va peor" (19/05/2018). Por su parte Laura, reconoce que ha tenido acceso a ciertos privilegios por ser güera, por ejemplo, ser "la imagen publicitaria de la escuela (...) o que a tu amigo de la primaria le gustaras tú y no tu amiga" (25/12/2018) aunque conscientemente no ha querido aprovecharse de esa circunstancia. Mientras que Irene no cree que ser "güera" haya representado ventajas para ella.

Finalmente los personajes retratados coincidieron en que, en algún momento de sus vidas, sus características físicas como güeros también los habian hecho objeto de insultos y/o de burlas, aunque esa circunstancia no había tenido las mismas consecuencias en todos los sujetos. Por ejemplo, a Gabriel cuando era niño le decían “ojos color de charco de agua puerca" por tener ojos verdes, pero nunca le afectó emocionalmente. Sin embargo, a Laura, que es albina y la llamaban "fantasmita" o "chango güero" le afectaba mucho el acoso por ser güera. Por su parte, Luis recuerda que a lo largo de su vida le han dicho "los insultos básicos: vende quesos, tripa de leche, güero de rancho, menonita, pero pues siento que nunca me han ofendido" (05/01/2018); por el contrario, siendo niño sentía que, podía defenderse llamando a los otros "prieto o negro", pues comparativamente eran peores insultos.

\section{Construir conocimientos sobre el racismo creando una serie fotográfica}

Para el fotógrafo, realizar "Todos güeros" implicó mirarse en el espejo de otros güeros y sus relatos de privilegio y, en consecuencia, indagar en su memoria, en su propia historia, identificando experiencias de desventaja por ser moreno. Esto lo llevó a emprender un proceso de autoconocimiento, y pensar ambas experiencias desde los estudios del racismo en México (Moreno, 2016). Como resultado de sus reflexiones, considera que el aprecio por "la blancura" y el racismo han estado presentes a lo largo de su vida como dos caras de la misma moneda. Recordó que no le gustaba su color de piel cuando era adolescente y ahora tiene claro que ese autodesprecio fue estimulado en buena medida por conversaciones casuales de su familia.

Recordó que sus padres le han llamado "negro" desde siempre, así ha crecido, es "su otro nombre" y aunque le encanta, desde muy joven aprendió que ser moreno trae más desventajas que ventajas frente a "ser güero". Por ejemplo, cuando tenía 12 años — y estaba de visita una tía a la que consideraban fashion porque vivía en la frontera y siempre traía cosas nuevas y cool - se preparaban para ir a una fiesta, su prima Laura tenía un vestido rojo vibrante, y su tía fashion dijo que "se le veía increíble el color rojo porque es blanca y le quedan todos los colores". Entonces se giró hacia él y le dijo: "a ti no, por ejemplo, porque tu piel es morena, tú no puedes usar rojo".

Contrastando su vida en México con su percepción de la realidad canadiense, aprendió que despreciar "lo moreno" frente a "lo güero" no es algo "natural", que el racismo y el "aprecio por la blancura" no son inevitables, inherentes a la vida en sociedad; sino que "se cultivan" de formas diversas y diferenciadas dependiendo de cada contexto. Le quedó claro que "todos conocemos sobre el racismo que existe en México, pero no ahondamos en de dónde proviene o qué origina este aprecio por lo blanco" y naturalizado asumimos que "así son las cosas" y no cuestionamos la legitimidad de ese estado de cosas.

El proceso de creación artística partió de reconocer que la colonialidad del ver (Barriendos, 2011) moldea la forma en la que construimos y consumimos narrativas, reproduciendo privilegios y desventajas en la representación de determinados sujetos y culturas. El fotógrafo asumió un posicionamiento decolonial y estableció como objetivo crear imágenes que contribuyeran a visibilizar el privilegio de "ser blanco" y el "aprecio por la blancura" que lo hace posible. En consecuencia, detonó reflexiones sobre la pertinencia social de que los fotógrafos cuestionen desigualdades en la representación de la diversidad desde un enfoque antirracista (Berman y Paradies, 2008) y desarrollen su práctica artística a través de un abordaje crítico de la realidad; para tratar de transformarla para construir el bien común en la diversidad.

En suma, desarrollando el proceso de creación artística, el fotógrafo generó conocimientos de orden histórico, sociológico y antropológico sobre la sociedad a la que pertenece; y sobre cómo emplear su formación artística para construir discursos críticos acerca de la representación visual y audiovisual de identidades en la diversidad. Crear "Todos güeros" lo llevó a ejercitar su 
capacidad crítica y a construir conocimientos sobre cómo ha vivido el racismo, y cómo se ha presentado a lo largo de su vida. Hizo evidente que tender puentes con otras disciplinas facilitó contextualizar el tema y el proceso de creación artística; enriquecer la comprensión de la realidad abordada.

\section{Reflexiones finales}

El proceso de creación fotográfica es un espacio que ofrece condiciones propicias para la construcción de conocimientos empíricos sobre cómo se expresa, experimenta y reproduce el "aprecio por la blancura" y el privilegio de "ser güero". Entrevistar y retratar a personajes preguntándoles qué ventajas o desventajas han experimentado por ser güeros genera relatos sobre cómo opera el aprecio por "la blancura" y el privilegio de "ser güero"; de ese modo las fotografías contribuyen a ponerle rostro a la categoría güero desde el estado de Veracruz, México. El diálogo entre fotógrafo y personajes no solo detona la construcción de conocimientos sobre el otro, sino también el autoconocimiento del fotógrafo quien ha relacionado su experiencia con la de los otros, y con la perspectiva teórica de los estudios del racismo en México (Moreno, 2016).

Por otra parte, la investigación documental le permitió comprender que el "aprecio por la blancura" y el privilegio de "ser güero" son consecuencia de procesos históricos fundamentados en la ideología mestizante (Gómez Izquierdo y Sánchez Díaz, 2012); y en base a ese conocimiento apostó por visibilizar y cuestionar los abusos de poder, la construcción de ventajas y desventajas en la diversidad; poniendo énfasis en cómo se experimenta el privilegio. Es decir, el proceso de creación fotográfica apostó por hacer de la producción artística un instrumento para erradicar el poder e influencia de la colonialidad del ver (Barriendos, 2011); ejerciendo el fotógrafo su poder para construir la realidad y su compromiso con la tarea de construir imaginarios igualitarios de la diversidad.

\section{Referencias}

Barriendos, J. (2011). La colonialidad del ver: hacia un nuevo diálogo visual interepistémico. Nómadas. 35: 13-29.

Berman, G. y Paradies, Y. (2008). Racism, disadvantage and multiculturalism: Towards effective anti-racist praxis. Ethnic and Racial Studies, 1-19.
Bonfil Batalla, G. (2010). México profundo, una civilización negada. México: Debolsillo.

Carrillo Quiroga, P. (2015). La investigación

basada en la práctica de las artes y los medios audiovisuales. Revista Mexicana de Investigación Educativa. 20, (64): 219-240.

El Diario. (2016). Denuncia racismo en TV mexicana. Consultado el 07/10/2018 en: http://diario. $\mathrm{mx} /$ Espectaculos/2016-07-08_86854922/denunciaracismo-en-tv-mexicana/

Gómez Izquierdo, J. (2005). Racismo y nacionalismo en el discurso de las élites mexicanas: Historia Patria y Antropología Indigenista. En Gómez Izquierdo, J. (Coord.). Los caminos del racismo en México. México: Plaza y Valdés.

Gómez Izquierdo, J. y Sánchez Díaz, M. E. (2012). La ideologia mestizante, el guadalupanismo y sus repercusiones sociales. México: UIA-BUAP.

INEGI. (2017). Presenta INEGI, por vez primera, resultados sobre la Movilidad Social Intergeneracional. 16 de junio de 2017. Consultado el 07/10/2018 en http://www.beta.inegi.org.mx/app/ saladeprensa/noticia.html?id=3556

Maristain, M. (2015). Es molesto el racismo de la televisión mexicana, dice la actriz Iazua Larios. Consultado el 07/10/2018 en http://www.sinembargo. $\mathrm{mx} / 21-09-2015 / 1490754$

Méndez, S. (2011). La población en el siglo XIX. En Aguilar, M. y Ortíz, J. (Coords.). (2011). Historia General de Veracruz. México: Gobierno del Estado de Veracruz, Secretaría de Educación del Estado de Veracruz, Universidad Veracruzana.

Molina, J. (2013). Los "representantes de México" no se parecen a los mexicanos. El País. Consultado el 07/10/2018 en http:// internacional.elpais.com/internacional/2013/08/21/ actualidad/1377057921_472827.html

Moreno, M. (2016). El archivo del estudio del racismo en México. Desacatos. 51, 143-177.

Pérez Morales, L.J. (2018). Todos güeros. [Fotografía]. Archivo personal del fotógrafo.

Sánchez, J. A. (2012). Pigmentocracia y medios de comunicación en el México actual: la importancia de las representaciones socio-raciales y de clase en la televisión mexicana. En Cairo; Cabezas.; Mallo; del Campo, ; Carpio. XV Encuentro de Latinoamericanistas Españoles, Nov 2012. Madrid: Trama editorial-CEEIB.

Zárate-Moedano, R. (2018). Alfabetización mediática decolonial para la formación de miradas antirracistas en la Universidad. Revista cientifica $R a-$ Ximhai. 14 (2). 